\author{
TrASExtonsion
}

\title{
Become Captain of Your Financial Ship, Unit 3: Standing Watch ${ }^{1}$
}

Josephine Turner ${ }^{2}$

This is Unit 3 in a 6-part series on improving personal financial management. Other publications in the series include:

Become Captain of Your Financial Ship: A Curriculum in Financial Management

Become Captain of Your Financial Ship, Unit 1: Charting the Course

Become Captain of Your Financial Ship, Unit 2: Standing Watch

Become Captain of Your Financial Ship, Unit 4: Stay the Course

Become Captain of Your Financial Ship: Evaluation Survey

Each unit includes PowerPoint handouts, class work, take-home assignments, and other resources.

Additional materials are available on the EDIS sebsite (http://edis.ifas.ufl.edu) and/or other websites as identified.

\author{
Unit 2 \\ This document is only available as a PDF. Click \\ here to access the PDF.
}

